\title{
ROUTINE HISTOPATHOLOGICAL EXAMINATION OF TWO COMMON SURGICAL SPECIMENS- APPENDIX AND GALL BLADDER, ITS USEFULNESS AND IMPACT ON PATIENT MANAGEMENT
}

\author{
Rohit Singh ${ }^{1}$, Hiren Kumar Bhattacharyya ${ }^{2}$
}

${ }_{1}^{1}$ MS, Department of General Surgery, GMCH, Assam, India.

2 Professor, Department of General Surgery, GMCH, Assam, India.

\begin{abstract}
BACKGROUND

Appendicectomy and cholecystectomy specimens removed from patients with suspected acute/ chronic appendicitis or cholecystitis often appear normal, but histopathological analysis of these cases may reveal a more ominous underlying pathology and hence a change in further management. However, a routine examination of all specimens is not well accepted owing to the fact that routinely doing a histopathological examination of all specimens is both money and time consuming. So, to address this question, we evaluated histopathological reports of 510 appendicectomy and cholecystectomy specimens at the Gauhati Medical College and Hospital, Guwahati (Assam) over a period of 1 year.
\end{abstract}

\section{MATERIALS AND METHODS}

Histopathology reports for all appendices and gall bladders removed were analysed at the GMCH between $1^{\text {st }}$ July 2016 and $30^{\text {th }}$ June 2017 and were reviewed by examination of the case notes. The analysis mainly focussed on the confirmation of inflammatory pathology, incidental unexpected findings other than inflammation, whether these unexpected findings were suspected on macroscopic examination at the time of surgery and the effect on patient management and prognosis.

\section{RESULTS}

The histopathology reports showed a variety of abnormal incidental lesions. Of the 250 appendicectomy specimens, 9 (3.6\%) revealed abnormal diagnoses other than inflammatory changes. Only 2 of 9 unexpected pathology (22.22\%) were suspected on macroscopic examination intraoperatively. Almost same results were seen on analyses of cholecystectomy specimens. Out of the 260 specimens, 11 (4.23\%) showed abnormal pathology and 7 (63.63\%) were suspected at the time of surgery.

\section{CONCLUSION}

Almost all of the specimens, which showed incidental abnormal findings had an impact on patient's management or outcome and most of them were not suspected on macroscopic examination at the time of surgery. These would have been missed had the specimens not been examined microscopically. The intra-operative diagnosis of the surgeon is therefore unreliable in detecting abnormalities of the appendix and gall bladder. This study supports the sending of all appendicectomy and cholecystectomy specimens for routine histopathological examination.

\section{KEY WORDS}

Appendicectomy, Cholecystectomy, Histopathology.

HOW TO CITE THIS ARTICLE: Singh R, Bhattacharyya HK. Routine histopathological examination of two common surgical specimens- appendix and gall bladder, its usefulness and impact on patient management. J. Evolution Med. Dent. Sci. 2018;7(33): 3687-3692, DOI: $10.14260 /$ jemds/2018/828

\section{BACKGROUND}

Histopathology (compound of three Greek words: histos "tissue," pathos "suffering" and logia "study of") refers to the microscopic examination of tissues in order to study the manifestations of diseases. Specifically, in clinical medicine histopathology refers to the examination of a biopsy or surgical specimen by a pathologist after the specimen has been processed and histological sections have been placed onto glass slides.

In view of surgical practice, Appendicectomy and Cholecystectomy are the most undertaken operative procedures in any hospital worldwide and the specimens are

'Financial or Other Competing Interest': None

Submission 04-07-2018, Peer Review 29-07-2018,

Acceptance 04-08-2018, Published 13-08-2018.

Corresponding Author:

Rohit Singh,

A-405, Panchachuli Apartments,

Sector-61, Noida-201301

Uttar Pradesh, India.

E-mail: rohitcaptain@gmail.com

DOI: $10.14260 /$ jemds $/ 2018 / 828$

regularly seen on a daily routine histopathological work of the pathology department. Conventionally, all specimens were sent to pathology department for histopathological examination as the dictum is that surgical specimens containing malignancies need accurate pathology reports for proper postoperative management (Strobel et al, 2006).[1]

However, in recent times this traditional view has been under challenge owing to the fact that routine histopathological examinations takes time, thus increasing the work load on pathologists as well as increased utilisation of hospital resources.

Hence, this study was undertaken to answer the following question- whether a routine histopathologic examination of two common surgical specimens (Appendix and Gallbladder) is needed or is it an extra expense on our usually understaffed and under resourced hospital personnels in our part of the world. Also, this study aims to assess the incidence of unexpected pathologic diagnoses and their impact on postoperative management. 


\section{Aims and Objectives}

The following study has been undertaken to fulfil the following objectives-

1. To study the incidence of unexpected pathological diagnoses of appendicular and gall bladder pathology.

This study mainly addresses the question of justification of routine histopathological examination of specimen of appendix and gall bladder in Indian scenario.

\section{MATERIALS AND METHODS}

It is a retrospective descriptive study which was undertaken in six Surgery Units of Gauhati Medical College and Hospital, Guwahati, Assam between $1^{\text {st }}$ July 2016 and $30^{\text {th }}$ June 2017. A total of 510 cases were included in the study.

\section{Inclusion Criteria}

All patients who presented with acute/ chronic appendicitis/ cholecystitis, either in emergency or surgery outpatient department of GMCH and who either underwent emergency or elective appendicectomy or cholecystectomy during the course of study were included. Patients of all age groups and both sex were included.

\section{Exclusion Criteria}

Patients having a clinical diagnosis or suspicion of malignancy/ unexpected pathology preoperatively were excluded.

\section{Informed Consent}

An informed consent was taken from all patients included in the study after explaining the need, cost and impact of histopathology report on post-operative management.

\section{Statistical Analysis}

All the data were collected, tabulated and analysed statistically. Statistical analysis was performed, and sensitivity of macroscopic examination was measured using appropriate formulae.

\section{Data Recording}

Histopathology reports of patients who underwent appendicectomy or cholecystectomy were analysed retrospectively. The case notes were retrieved and correlated with the histopathological findings. The incidence and impact of unexpected pathological findings on post-operative management were noted. The clinical diagnosis was determined based on patient's history, investigations and intra-op findings.

The surgeries were performed by 17 different surgeons of the Dept. of Surgery, GMCH, Guwahati. The specimens were sent for histopathology to the Dept. of Pathology, GMCH, Guwahati and reports retrieved.

A proforma was made for each patient and all relevant data was maintained for subsequent analysis of result and final conclusion.

\section{RESULTS}

The observations and the results of our study have been elaborated as follows-

\section{The Vermiform Appendix}

A total of 250 patients who underwent appendicectomy were included in our study.

Out of the 250 patients who underwent appendicectomy, $8 \%(n=20)$ had normal histopathology, 24.8\% ( $n=62)$ showed histopathological features of acute appendicitis, $2.8 \%$ $(n=7)$ showed acute on chronic appendicitis, 60.8\% $(n=152)$ showed chronic appendicitis and 3.6\% (n= 9) showed unexpected findings (Table 1 ).

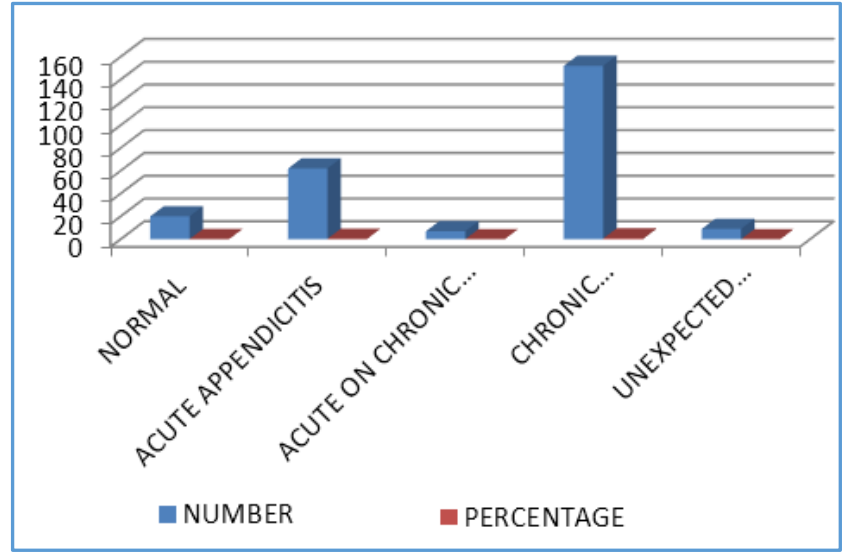

Table 1

\section{Unexpected Findings}

Out of the 9 unexpected histopathological findings, mucocele was most common $(33.33 \%, n=3)$. Tubercular appendicitis and adenocarcinoma both were present in $22.22 \%(n=2)$ of specimens. Others included carcinoid appendix $(11.11 \%$, $\mathrm{n}=1)$ and presence of parasite in appendix $(11.11 \%, \mathrm{n}=1)$, (Table 2).

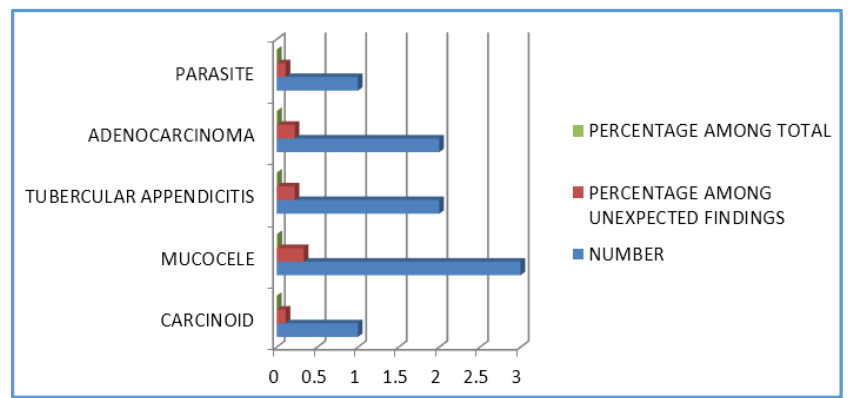

Table 2

The 9 unexpected findings were correlated with case notes and intraoperative findings by the surgeon. Whether the surgeon found any abnormality or not intraoperatively was noted. Following findings were observed (Table 3).

\begin{tabular}{|c|c|c|}
\hline Macroscopic abnormality found & 2 & $22.22 \%$ \\
\hline Macroscopic abnormality not found & 7 & $77.77 \%$ \\
\hline \multicolumn{2}{|c|}{ Table 3 } \\
\hline
\end{tabular}

\section{Gall Bladder}

A total of 260 patients who underwent cholecystectomy were included in our study.

Out of the 260 patients who underwent cholecystectomy, $6.92 \%(n=18)$ of patients showed pathological changes consistent with acute inflammation, $0.77 \%(\mathrm{n}=2)$ showed 
acute on chronic inflammation $(\mathrm{n}=2), 88.08 \%(\mathrm{n}=229)$ showed chronic inflammation and $4.23 \%(n=11)$ patients showed unexpected findings (Table 4).

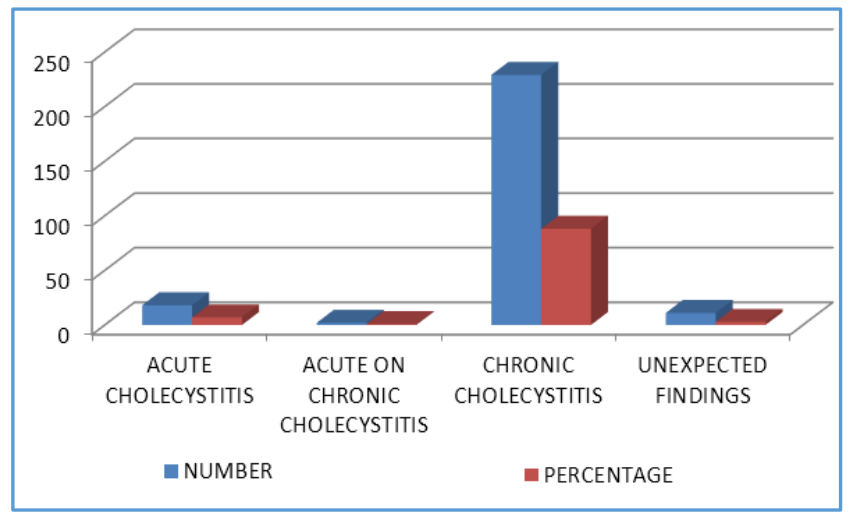

Table 4

\section{Unexpected Findings}

Out of the 11 unexpected histopathological findings, polyp was the most common finding $(36.37 \%, n=4)$. Gall bladder cancer was the $2^{\text {nd }}$ most common unexpected finding $(27.27 \%, \mathrm{n}=3)$. Others included adenomyoma $(9.09 \%, \mathrm{n}=1)$, papillary hyperplasia $(9.09 \%, n=1)$, cholesterolosis $(9.09 \%$, $\mathrm{n}=1)$ and xanthogranulomatous cholecystitis $(9.09 \%, \mathrm{n}=1)$ (Table 5).

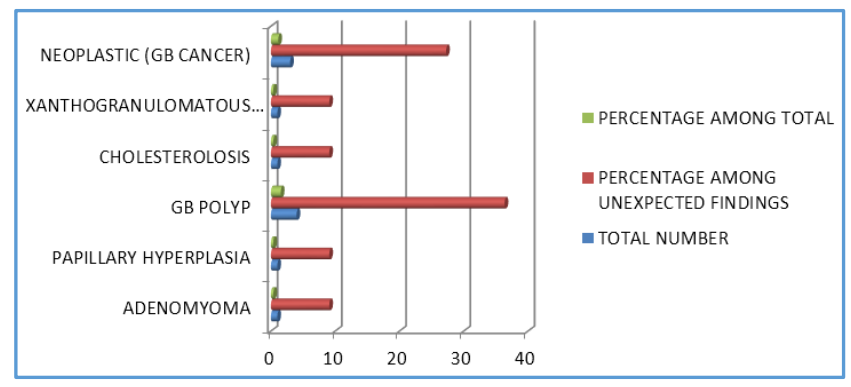

Table 5

The 11 unexpected findings were correlated with case notes and intraoperative findings by the surgeon. Whether the surgeon found any abnormality or not intraoperatively was noted. Following findings were observed (Table 6).

\begin{tabular}{|c|c|c|}
\hline Macroscopic abnormality found & 7 & $63.63 \%$ \\
\hline Macroscopic abnormality not found & 4 & $36.36 \%$ \\
\hline Table 6 \\
\hline
\end{tabular}

Overall Sensitivity of Macroscopic Examination by the Surgeon and Statistical Analysis

On examining all the results of unexpected pathologies of appendix and gall bladder, we find the overall sensitivity of macroscopic examination to be $45 \%(9 / 20)$. 55\% (11/20) unexpected pathologies could have been missed if we had adopted a selective policy for sending specimens for histopathology.

Overall Impact on Further Management of Patients Diagnosed with Unexpected Findings

All patients (100\%) diagnosed with unexpected findings underwent further management in some form or the other, which is discussed in subsequent paragraphs.

\section{DISCUSSION}

Keeping in mind the contrasting studies which exists in literature, this study was done to address the following question-

"Whether or not all specimens of cholecystectomy and appendicectomy should be sent for histopathology even after preoperative and intraoperative normal findings."

\section{THE VERMIFORM APPENDIX}

It is the retrospective analysis of the histopathology reports of 250 appendicectomy cases that will answer the question of importance of routine histopathological analysis.

We found 9 out of 250 specimens (3.6\%) harbouring unexpected pathologies.

These findings are very much comparable to a study done by Jones et al[2] with 1225 appendicectomy specimens. They reported unexpected pathologies in 46 cases $(3.76 \%)$ Akbulut et $\mathrm{al}^{[3]}$ reported unexpected findings in $1 \%$ (54/5462) of patients.

The following tables enumerates the incidence of unexpected pathologies in previous studies (Table 7).

\begin{tabular}{|c|c|}
\hline Studies & $\begin{array}{c}\text { Percentage of Unexpected } \\
\text { Pathologies }\end{array}$ \\
\hline Marudanayagam R $^{4}$ & $1.51 \%$ \\
\hline Khan OA $^{5}$ & $4.2 \%$ \\
\hline Chamisa $^{6}$ & $8.6 \%$ (All Parasite) \\
\hline Akbulut S $^{3}$ & $1 \%$ \\
\hline Chandrasegaram MD $^{7}$ & $3.2 \%$ \\
\hline Yabanoglu H $^{8}$ & $3.9 \%$ \\
\hline Ramraje & $1.23 \%$ \\
\hline Present Study & $3.6 \%$ \\
\hline \multicolumn{2}{|c}{ Table 7 } \\
\hline
\end{tabular}

The Unexpected Findings in Our Study Included-

1. Mucocele-3/250 (1.2\%)

2. Tubercular appendicitis- $2 / 250(0.8 \%)$

3. Adenocarcinoma of appendix- $2 / 250(0.8 \%)$

4. Carcinoid- $1 / 250(0.4 \%)$

5. Intraluminal parasite- $1 / 250(0.4 \%)$

The existing literature reports that only in $0.1-4.2 \%$ of routine histopathologic evaluations does one see abnormal diagnoses other than normal or inflammatory changes, which is quite consistent with our findings.

Appendiceal cancer is exceedingly rare, accounting for $0.5 \%$ of all gastrointestinal neoplasms with the age-adjusted incidence of 0.12 case per $1,000,000$ people per year. Owing to its vague and bizarre presentations, primary appendiceal cancer cannot be diagnosed preoperatively and is diagnosed in only $0.9 \%-1.4 \%$ of appendectomy specimens. These findings were reported by O'Donnell ME et al[10] and quite consistent with our result.

Most important however is the fact that all patients with unexpected findings had to undergo further intervention in one way or the other.

The patients diagnosed with tubercular appendicitis had no previous or present history of concomitant pulmonary disease. Both the patients diagnosed with tubercular appendicitis had to start their anti-tubercular regimens as Category 1 TB patients. The patient diagnosed with intraluminal parasite had to start anti-helmintic drugs. 
The patients diagnosed with mucocele had to be regularly followed up and the presence of peritoneal collection due to probable seeding of mucinous cells (Pseudomyxoma peritonei) during appendicectomy had to be keenly observed by repeated ultrasounds at regular intervals.

Other patients with carcinoid or adenocarcinoma as their finding had to undergo complete workup with CT scan, colonoscopy and relevant blood investigations so as to rule out concomitant colonic malignancy and also to study the extent of the disease spread. The decision for re-laparotomy for right-sided hemicolectomy or chemotherapy is yet to be taken.

These unexpected findings give routine histopathological examination much more credibility owing to the fact that not all abnormal findings can be detected by macroscopic examination. Jones et al[2] reported that macroscopy by the surgeon is not sufficient to rule out unexpected pathology, as only 2 out of his 46 unexpected findings could be detected intraoperatively by the surgeon.

In our study also, only 2 out of 9 (22.22\%) unexpected pathologies could be identified macroscopically and the rest 7 would have been missed if they had not been subjected to routine examination.

Thus, concluding we can say that although fecoliths and lymphoid hyperplasia are the common aetiologies of acute appendicitis, some rare but vitally fatal lesions may also cause appendicitis. On the same note, intraoperative observations alone are not enough to identify the unexpected disease. Although, the routine histological examination of appendectomy specimens poses a burden on the financial and technical resources, current research strongly justifies this practice. Specimens from patients with suspected acute appendicitis may exhibit countless histological variations including cancerous growths. The histologic examination is valuable in identifying unexpected conditions, which may require further management depending on the nature of the disease process.

\section{Gall Bladder}

Gall bladder carcinoma accounts for $98 \%$ of all the gall bladder malignancies and it is the sixth most common malignancy of the gastrointestinal tract worldwide. The incidence of incidental gall bladder carcinoma, which is diagnosed during or after a laparoscopic cholecystectomy is reported to be around $0.19-3.3 \%$ in the literature.

GBC is known for the striking gender, geographic and ethnic variation in worldwide incidence, suggesting a strong influence of genetic and environmental factors. GBC is rare in most of Northern Europe and North America. The highest rates of GBC are found in northern India and Pakistan, East Asia (Korea and Japan), Eastern Europe (Slovakia, Poland and Czech Republic) and South America (Columbia and Chile).

Rates may vary even within a region or a country. This fact can be well demonstrated in a country like India with extreme geographic and environmental variations. Incidence of GBC in women in northern India is as high as 9 per 100,000 per year as compared to as low as 1 per 100,000 per year in southern India.[11] In areas of high prevalence, GBC is one of the most common gastrointestinal cancers, especially in women.
Before we begin our discussion, let us take a look at some of the studies done in the past on this subject (Table 8).

\begin{tabular}{|c|c|c|c|c|c|}
\hline 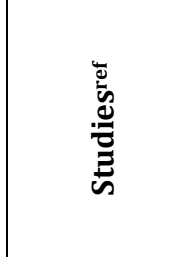 & 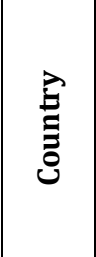 & 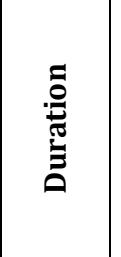 & 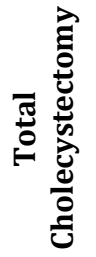 & 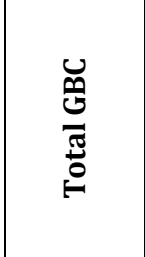 & 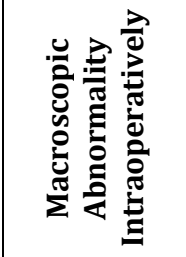 \\
\hline Darmas 12 & UK & 5 years & 1452 & $4(0.27 \%)$ & All $4(100 \%)$ \\
\hline Taylor13 & UK & 7 years & 1078 & $6(0.55 \%)$ & All $6(100 \%)$ \\
\hline $\operatorname{Dix}^{14}$ & UK & 4 years & 1308 & $5(0.3 \%)$ & All $5(100 \%)$ \\
\hline Matthyssens ${ }^{1}$ & France & \begin{tabular}{|c|}
10 \\
years
\end{tabular} & 1523 & $6(0.4 \%)$ & All $6(100 \%)$ \\
\hline Bazoua16 & UK & $\begin{array}{c}10 \\
\text { years }\end{array}$ & 2890 & $5(0.17 \%)$ & All $5(100 \%)$ \\
\hline Oommen 17 & UK & 4 years & 976 & $1(0.01 \%)$ & - \\
\hline \multicolumn{6}{|c|}{ Table 8} \\
\hline
\end{tabular}

The above-mentioned studies are those who advocate a selective approach while sending a cholecystectomy specimen for histopathology, as they found macroscopic abnormalities in all cases which were after histopathology diagnosed to be GBC. This fact however needs a little explanation and the term IGBC (Incidental Gall Bladder Cancer) needs to be defined. ${ }^{18,19}$

"GBC diagnosed for the first time on histology of GB removed with a presumed diagnosis of gallstone disease is known as incidental GBC (IGBC). The term IGBC should not be used when GBC is suspected either on pre-operative imaging (Ultrasonography [US] or CT scan) during surgery or on opening the GB specimen."

Therefore, none of the above studies mentioned above had findings of incidental GBC. Thus, strictly speaking these were cases of GBC that were actually picked up pre- or intraoperatively and the true incidental GBC were less frequent. Most cases were advanced, and no further therapy was considered; prognosis was uniformly poor. With such low rates of detection of disease necessitating any change in management, authors proposed a selective policy of examining only grossly suspicious GBs. This may be due to the fact that the above studies were done in low risk area of the world (UK and France). ${ }^{20}$

However, the findings of our study differ from studies recommending selective approach. 11 out of 260 cholecystectomy $(4.23 \%)$ specimens harboured unexpected pathology. Our study is conducted in a geographical area, which has a high incidence of GBC. Thus, findings of incidental GBC (IGBC) are more frequent in our study. 3 cases out of 260 were reported to be GBC with 2 cases having no macroscopic abnormality intraoperatively, while 1 had obvious macroscopic changes. Thus, in our study finding of incidental GBC was 2/260 (0.77\%), which was well within the range of worldwide incidence of IGBC found in the literature. ${ }^{21,22}$

Moreover, in our study GBC which were identified by histopathology were in the stage where re-exploration will definitely have a positive impact on the outcome of the patient (1 in T1a stage, 2 in T2 stage). 
In our present study, we report 3 neoplastic lesions on histopathology out of the 260 cholecystectomy specimens out of which one could be correctly identified macroscopically by the operating surgeon. Thus, in our study true IGBC findings comes out to be 2 out of 260 cases $(0.77 \%)$. This value is well within the range of values reported by previous studies.

All patients whose HPE reports came out to be neoplastic and more than $50 \%$ patients who had other unexpected findings in their histology had to undergo a certain additional intervention after their histopathology reports either in the form of re-exploration or follow-up. ${ }^{23}$

Last but not the least is the medico-legal aspect. None of the studies that suggests selective histology drew attention to the possible medico-legal consequences of a missed IGBC that may appear as a symptomatic lesion after the cholecystectomy.

Doing a routine histopathological examination may be a little monetary burden on part of the patient, but it will definitely save the surgeon from possible future lawsuits in case of a missed GBC.

\section{CONCLUSION}

Histopathology has been aiding us in surgical settings since its advent. It provides us with a more detailed insight into the patient's pathology, so as to help in the management of the disease condition of the patient. After a simple appendicectomy or cholecystectomy operation, the need for a histology report substantially increases as a large number of them may harbour a pathology, which has been missed in preoperative analysis and which may require an additional intervention depending upon the patient's pathology.

Less importantly, the histopathology report forms a part of a documented evidence in medico-legal cases and justifies the actions of a treating doctor.

However, with all its advantages, histopathology comes with a cost, i.e. monetary expenditure on part of the patient as well as time and use of resources on part of the hospital. But its role cannot be undermined, as the body harbours things which the eyes cannot see.

The latest recommendations from the UK Royal College of Pathologists in 2005 state that all gallbladders removed for benign disease should be examined as significant pathology may be present with normal gross morphology.

Recommendations for routine histology of GB specimens should take into consideration local incidence rates of GBC. A selective policy may be safe and cost beneficial in areas with very low incidence of GBC. This would include most countries of the West.

In the Indian scenario, we strongly advise that all GBs removed for presumed gallstone disease should be opened up by the surgeon in the operating room for a careful gross examination. If changes suspicious of malignancy are seen, the GB should be subjected to a frozen section examination and if it is positive an extended cholecystectomy should be performed. If no changes suspicious of malignancy are seen, at least in northern and north-eastern India the GB should be subjected to routine histological examination to detect an incidental GBC so that re-resection with a hope for long-term survival may be offered to the patient.

The same goes for appendicectomy specimens. There are very few studies, which evaluate the benefits of analysing appendicectomy specimens. As a result, some centres send specimens only if they appear macroscopically abnormal at the time of surgery. This practice has the potential to miss important diagnoses, as it is now a known fact that a normal appendix may hide unexpected/ abnormal pathologies, which may subsequently affect patient's management and if missed may also cause the surgeon to land up in a courtroom trouble.

Thus, this study conducted in present Indian scenario strongly recommends the routine use of histopathology of the two common surgical specimens- Appendix and Gall Bladder.

\section{REFERENCES}

[1] Strobel SL. Enhancing the pathologist's role at hospital tumor boards. Ann Clin Lab Sci 2006;36(3):243-7.

[2] Jones AE, Phillips AW, Jarvis JR, et al. The value of routine histopathological examination of appendicectomy specimens. BMC Surgery 2007;7:17.

[3] Akbulut S, Tas M, Sogutcu N, et al. Unusual histopathological findings in appendectomy specimens: a retrospective analysis and literature review. World J Gastroenterol 2011;17(15):1961-70.

[4] Marudanayagam R, Williams GT, Rees BI. Review of the pathological results of 2660 appendicectomy specimens. J Gastroenterol 2006;41(8):745-9.

[5] Khan OA, Morhan A, Jegatheeswaran S, et al. Routine pathological analysis of appendicectomy specimens--is it justified? Acta Chir Belg 2007;107(5):529-30.

[6] Chamisa I. A clinicopathological review of 324 appendices removed for acute appendicitis in Durban, South Africa: a retrospective analysis. Ann R Coll Surg Engl 2009;91(8):688-92.

[7] Chandrasegaram MD, Rothwell LA, An EI, et al. Pathologies of the appendix: a 10-year review of 4670 . appendicectomy specimens. ANZ J Surg 2012;82(11):844-7.

[8] Yabanoglu H, Caliskan K, Aytac HO, et al. Unusual findings in appendectomy specimens of adults: retrospective analyses of 1466 patients and a review of literature. Iran Red Crescent Med J 2014;16(2):e12931.

[9] Ramraje SN, Pawar VI. Routine histopathologic examination of two common surgical specimens appendix and gallbladder: is it a waste of expertise and hospital resources? Indian J Surg 2014;76(2):12730.

[10] O'Donnell ME, Badger SA, Beattie GC, et al. Malignant neoplasms of the appendix. International Journal of Colorectal Disease 2007;22(10):1239-48.

[11] National Cancer Registry Programme. Two-year Report of the Population Based Cancer Registries, 1997-1998. ICMR, Bangalore 2002.

[12] Darmas B, Mahmud S, Abbas A, et al. Is there any justification for the routine histological examination of straightforward cholecystectomy specimens? Ann R Coll Surg Engl 2007;89(3):238-41.

[13] Taylor HW, Huang JK. 'Routine' pathological examination of the gallbladder is a futile exercise. $\mathrm{Br} \mathrm{J}$ Surg 1998;85(2):208.

[14] Dix FP, Bruce IA, Krypcyzk A, et al. A selective approach to histopathology of the gallbladder is justifiable. Surgeon 2003;1(4):233-5. 


\section{Jemds.com}

[15] Matthyssens LE, Ziol M, Barrat C, et al. Routine surgical pathology in general surgery. $\mathrm{Br} J$ Surg 2006;93(3):362-8.

[16] Bazoua G, Hamza N, Lazim T. Do we need histology for a normal-looking gallbladder? J Hepatobiliary Pancreat Surg 2007;14(6):564-8.

[17] Oommen CM, Prakash A, Cooper JC. Routine histology of cholecystectomy specimens is unnecessary. Ann R Coll Surg Engl 2007;89(7):738-9.

[18] Samad A. Gall bladder carcinoma in patients undergoing cholecystectomy for cholelithiasis. J Pak Med Assoc 2005;55(11):497-9.

[19] Khan MA, Khan RA, Siddiqui S, et al. Occult carcinoma of gallbladder: incidence and role of simple cholecystectomy. JK Pract 2007;14(1):22-3.

\section{Original Research Article}

[20] Khoo JJ, Nurul AM. A clinicopathological study of nine cases of gallbladder carcinoma in 1122 cholecystectomies in Johor, Malaysia. Malays J Pathol 2008;30(1):21-6.

[21] Lohsiriwat V, Vongjirad A, Lohsiriwat D. Value of routine histopathologic examination of three common surgical specimens: appendix, gallbladder and hemorrhoid. World J Surg 2009;33(10):2189-93.

[22] Behari A, Kapoor VK. Does gallbladder divide India? Indian J Gastroenterol 2010;29(1):3-7.

[23] Shrestha R, Tiwari M, Ranabhat SK, et al. Incidental gallbladder carcinoma: value of routine histological examination of cholecystectomy specimens. Nepal Med Coll J 2010;12(2):90-4. 